\title{
Comparative Effect of Calcium Mesoporous Silica Versus Calcium and/or Fluoride Products on the Reduction of Erosive Tooth Wear and Abrasive Enamel Lesion
}

\author{
Isabella Barbosa dos Santos Justino ${ }^{1}(\mathbb{0}$, Adílis Kalina Alexandria1,2®D, Fernanda Michel Tavares \\ Canto $^{1}{ }^{\circledR}$, Karla Lorene de França Leite ${ }^{\circledR}$, Thiago Isidro Vieira ${ }^{1}$, Lucio Mendes Cabral ${ }^{\circledR}{ }^{\circledR}$, Raphael \\ Ferreira da Silva ${ }^{3}$ (D), Lucianne Cople Maia ${ }^{1}(\mathbb{0})$
}

\begin{abstract}
${ }^{1}$ Department of Pediatric Dentistry and Orthodontics, Federal University of Rio de Janeiro, Rio de Janeiro, RJ, Brazil. ${ }^{2}$ Department of Preventive and Community Dentistry, Rio de Janeiro State University, Rio de Janeiro, RJ, Brazil. ${ }^{3}$ Department of Drugs and Medicines, School of Pharmacy, Federal University of Rio de Janeiro, Rio de Janeiro, RJ, Brazil.
\end{abstract}

Author to whom correspondence should be addressed: Lucianne Cople Maia, Rua Rodolpho Paulo Rocco, 325, Cidade Universitária, Rio de Janeiro, RJ, Brazil. 21941-913. Phone: +55 2139382098. E-mail: rorefa@terra.com.br.

Academic Editor: Alessandro Leite Cavalcanti

Received: 02 March 2020 / Accepted: 20 April 2020 / Published: 25 July 2020

How to cite this article: Justino IBS, Alexandria AK, Canto FMT, Leite KLF, Vieira TI, Cabral LM, et al. Comparative effect of calcium mesoporous silica versus calcium and/or fluoride products on the reduction of erosive tooth wear and abrasive enamel lesion. Pesqui Bras Odontopediatria Clín Integr. 2020; 20:e0025. https://doi.org/10.1590/pboci.2020.146

\begin{abstract}
Objective: To evaluate the effect of a calcium nanocompound on the reduction of erosive tooth wear and abrasion. Material and Methods: Bovine enamel specimens (BE), were randomly assigned to the following groups $(\mathrm{n}=10)$ : $\mathrm{G} 1$ = Calcium mesoporous silica nanoparticles $\left(\mathrm{Ca}^{2+} \mathrm{MSNs}\right)$; $\mathrm{G} 2$ = casein phosphopeptideamorphous calcium phosphate (CPP-ACP, $2 \%$ CPP-ACP, GC $\left.{ }^{\circledR}\right)$; $\mathrm{G} 3$ = casein phosphopeptide-amorphous calcium fluoride phosphate (CPP-ACFP, $2 \%$ CPP-ACP + 900 ppm F-, $\mathrm{GC}^{\circledR}$ ); $\mathrm{G} 4=$ sodium fluoride $\mathrm{NaF}$ (900 ppm F-, positive control); and G5 = distilled and deionized water (negative control). Each product was applied to the exposed area for one minute, three times per day for three consecutive days, and followed by the immersion of the specimens in Sprite Zero $^{\mathrm{TM}}$ - a low-pH solution (2.58) for five minutes (Coca-Cola ${ }^{\mathrm{TM}}$ ). After the first and last erosive challenges of the day, the specimens were submitted to abrasion in a toothbrush machine for 15 seconds ( $200 \mathrm{~g} / \mathrm{BE})$. The specimens were analysed using $3 \mathrm{D}$ non-contact optical profilometry, with tooth structure loss (TSL) measurements and scanning electron microscopy (SEM). TSL values were analysed by Kruskal-Wallis and Mann-Whitney tests $(\mathrm{p}<0.05)$. Results: There were no significant differences between G1 $(10.95 \mu \mathrm{m})$ and G3 $(10.80 \mu \mathrm{m})$ treatments for TSL values; however both resulted in significantly reduced TSL values compared with the G5 $(16.00 \mu \mathrm{m})(\mathrm{p}<0.05)$. The G4 $(12.26 \mu \mathrm{m})$ showed no statistically significant difference when compared to the G5 $(16.00 \mu \mathrm{m})$. The groups G1 and G3 presented higher surface preservation than the G5. Conclusion: $\mathrm{Ca}^{2+} \mathrm{MSN}$ s was effective for reducing tooth surface loss caused by erosive tooth wear and abrasion.
\end{abstract}

Keywords: Tooth Erosion; Tooth Abrasion; Sodium Fluoride; Calcium. 


\section{Introduction}

The erosive tooth wear is a process of cumulative loss of tooth structure through a chemicalmechanical process where this dissolution is not caused by bacteria [1,2]. The erosive tooth wear leads to the reduction of microhardness and the softening of the dental surface, which consequently becomes more susceptible to disruption by mechanical impacts [1,3].

Dental abrasion is a clinical condition of pathological tooth structure loss caused by mechanical forces applied to the teeth [3]. More significant levels of tooth wear are caused by the abrasivity of toothpastes than by the mechanical force applied by the toothbrush. Because the tooth structure becomes softened, brittle and more susceptible to wear after the erosive process begins, abrasion becomes more critical, even in cases where toothpaste is not used for brushing [4].

Regarding the preventive effect of different toothpastes abrasivity in an initial erosion-abrasion model, products that containing fluoride exhibited better efficacy for permanent and deciduous teeth [5]. Fluoride compounds have great preventive and therapeutic effects against tooth mineral loss [6,7], due to the formation of fluorapatite, which has significantly lower solubility than hydroxyapatite, and the formation of calcium fluoride $\left(\mathrm{CaF}_{2}\right)$ [1,8]; $\mathrm{CaF}_{2}$ can act as a physical barrier that prevents the penetration of acids into the underlying enamel layer, and an increasing number of studies have reported that this effect also protects against erosive tooth wear [9-11].

Other compounds have been studied, either alone or in combination with fluoride, in the search for better protection against tooth demineralisation [12,13]. Casein phosphopeptide-amorphous calcium phosphate (CPP-ACP) is a nanocomplex that promotes the stabilization of high levels of calcium (Ca) and phosphate $\left(\mathrm{PO}_{4}\right)$, providing a source of bioavailable ions for use during the remineralisation process $[14,15]$. In addition, CPP-ACP nanocomplexes can interact with fluoride ions to produce an amorphous calcium fluoride phosphate (ACFP) phase, which can provide an additional benefit due to the presence of fluoride within the nanocomplex $[13,16]$.

Mesoporous silica nanoparticles (MSNs) have also been recently studied in combination with varying dental materials. The structural and chemical properties of MSNs facilitate the aggregation of multiple ions and drugs, which can be selected according to the pore size of the nanoparticles or be immobilized on the nanoparticle surface $[17,18]$. MSNs have a high pore volume and a large surface area, which enables the association of large amounts of molecules or ions [17]. Thus, as a high-standard carrier, mesoporous silica can increase the bioavailability of aggregated nanoparticles [19], such as calcium, and potentialize the remineralisation process.

Due to the increased incidence of non-carious lesions, resulting from changes in eating habits and the increased consumption of acidic drinks [20,21], there has been a growing demand for studies of substances that are capable of reducing erosive tooth wear. Therefore, this study aimed to evaluate the effect of reducing the enamel dissolution with the use of new mesoporous calcium silica nanoparticles $\left(\mathrm{Ca}^{2+} \mathrm{MSNs}\right)$ in vitro after erosion-abrasion challenges, evaluating the loss of tooth structure (TSL). The null hypothesis of the present study is that the application of mesoporous silica nanoparticles to dental enamel does not minimize the loss of tooth structure (TSL) after an erosive and abrasive challenge compared to common products used in dental practice.

\section{Material and Methods}

Preparation of the Specimens 
Fifty specimens $(4 \times 4 \mathrm{~mm})$ were prepared from bovine incisors that were properly stored in a $2 \%$ formaldehyde solution. The dental enamel blocks were cut using an Isomet low-speed saw cutting machine (Buehler Ltd., Lake Bluff, Illinois, United States) with two diamond discs (Extec Corp., Enfield, Connecticut, United States), which were separated by a 4-mm-thick spacer. Then, the specimens were polished by using water-cooled silicon carbide paper 600, 800 and 1,200 (Extec Corp., Enfield, Connecticut, United States).The specimens were selected according to superficial microhardness using a microhardness tester (Micromet 5104; Buehler, Mitutoyo Corporation, Tokyo, Japan) containing a Knoop diamond (50 g, 5 s, 3 indentations spaced $100 \mathrm{~mm}$ apart). Enamel blocks with the overall average of $321.39\left(\mathrm{Kg} / \mathrm{mm}^{2}\right) \pm 10 \%$ were selected for the experiment.

Half of the surface of each specimen was covered with an acid-resistant nail varnish (Colorama, L'Óreal, Clichy, France) to create an unexposed area (control side) that could be compared with the area that was exposed to the erosive/abrasive challenge (experimental side).

\section{Group Allocation}

The enamel blocks were randomly allocated among the following groups $(\mathrm{n}=10)$ : $\mathrm{G} 1, \mathrm{Ca}^{2+} \mathrm{MSNs}$; G2, CPP-ACP slurry (2\% CPP-ACP, GC America Inc., Alsip, USA); G3, CPP-ACFP slurry (2\% CPP-ACP, 900 ppm F-, GC America Inc., Alsip, USA); G4, NaF (900 ppm F-, positive control); and G5, water $\left(\right.$ Milli- $^{\circledR}$, negative control).

A blinded researcher used a pipette to precisely apply $50 \mu \mathrm{l}$ of each treatment to the corresponding specimens. The treatment remained on the specimens for 1 minute. Then, the samples were rinsed with distilled and deionized water $\left(\right.$ Milli- $\left.\mathrm{Q}^{\circledR}\right)$. The treatment was performed 3x/day, for three consecutive days, with a two-hour interval between each treatment.

\section{Experimental Protocols}

The sample size of 10 specimens was calculated by BioEstat software version 5.3 (Instituto de Desenvolvimento Sustentável Mamirauá, Belém, PA, Brazil), using an $\alpha$-error level of $5 \%$ and a $\beta$-error level of $20 \%$, based on previous data, for the detection of a $10 \%$ difference in the loss of superficial microhardness [22].

$\mathrm{Ca}^{2+}$ MSNs suspension was prepared at Laboratório de Tecnologia Industrial Farmacêutica, Faculty of Pharmacy, Federal University of Rio de Janeiro. The CPP-ACP, CPP-ACFP treatments are commercially available as toothpastes were prepared as slurries (toothpaste/deionized water, 1:3 w/w) and NaF.

The specimens were submitted to three days of erosion/abrasion cycles, and the treatments were always performed just before to an erosive/abrasive challenge.

Each product was applied to the exposed area for one minute using a pipette $(100 \mu \mathrm{l})$ three times per day for three consecutive days, with an interval of 2 hours of each treatment on the same day and after treatment, the surfaces were washed with deionized water. The cycle of the erosion challenge was performed in the previously treated blocks using freshly opened bottles of Sprite Zero $(\mathrm{pH}$ 2.58, $30 \mathrm{~mL} / \mathrm{specimen}$; Coca-Cola Company, Atlanta, Georgia, USA), 4 times daily, for 5 min each [22]. After the erosion protocol, the specimens were rinsed in distilled and deionized water for $5 \mathrm{~s}$

The specimens were also abraded twice daily, using a mechanical toothbrush machine (Buehler Ltd., Lake Bluff, Illinois, United States) and fresh slurries (0.5 mL/specimen) containing unfluoridated toothpaste (toothpaste/water ratio 1:3; Daut Company, Rio de Janeiro, RJ, Brazil) for $15 \mathrm{~s} \mathrm{(50} \mathrm{strokes/s),} \mathrm{with} \mathrm{a} \mathrm{weight} \mathrm{of}$ $200 \mathrm{~g}[22]$, after the first and last erosive challenges each day. After each cycling the specimens remained for 
two hours in artificial saliva until the next cycle, and after the last daily cycle, the specimens were stored in artificial saliva $(1.5 \mathrm{mmol} / \mathrm{L}$ of calcium, $0.9 \mathrm{mmol} / \mathrm{L}$ of phosphate, $0.15 \mathrm{M}$ of potassium chloride, Tris buffer, and $0.05 \mu \mathrm{g}$ of fluoride $/ \mathrm{mL}$ ) overnight at $37^{\circ} \mathrm{C}$. (Table 1 ).

Table 1. Composition of the products used in the study.

\begin{tabular}{|c|c|}
\hline Products & Composition \\
\hline $\mathrm{Ca}^{2+}-\mathrm{MSNs}$ & $1 \mathrm{~g}$ of mesoporous silica doped with calcium powder to $100 \mathrm{~mL}$ of Milli- ${ }^{\circledR}$ water \\
\hline CPP-ACP & $\begin{array}{l}\text { Pure Water, Glycerol, CPP-ACP ( } 2 \% \text { CPP-ACP and } 900 \mathrm{ppm} \text { F-), D-Sorbitol, Silicon } \\
\text { Dioxide, CMC-Na, Propylene glycol, Titanium dioxide, Xylitol, Phosphoric acid, Guar } \\
\text { gum, Zinc Oxide, Sodium Saccharin, Ethyl p-hydroxybenzoate, Propyl p-hydroxybenzoate }\end{array}$ \\
\hline CPP-ACFP & $\begin{array}{l}\text { Pure Water, Glycerol, CPP-ACP, D-Sorbitol, Silicon Dioxide, CMC-Na, Propylene glycol, } \\
\text { Titanium dioxide, Xylitol, Phosphoric acid, Sodium fluoride, Guar gum, Zinc Oxide, } \\
\text { Sodium Saccharin, Ethyl p-hydroxybenzoate, Propyl p-hydroxybenzoate }\end{array}$ \\
\hline $\mathrm{NaF}$ & $\begin{array}{l}\text { Calcium Carbonate, Water, ethyl alcohol, Sodium bicarbonate, Sodium Lauryl Sulfate, } \\
\text { Sodium Monofluorophosphate ( } 900 \mathrm{ppm} \mathrm{F-)} \mathrm{and} \mathrm{Glycerin}\end{array}$ \\
\hline Unfluoridated Toothpaste & $\begin{array}{l}\text { Cellulose Gum, Glycerin, Malva Sylvestris \{Mallow\}Extract Silica, Sodium Benzoate, } \\
\text { Sodium Lauroyl Sarcosinate, Sucralose,Xylitol,Flavor, CI } 45430 \text {, Aqua }\end{array}$ \\
\hline Artificial Saliva & $\begin{array}{l}1.5 \mathrm{mmol} / \mathrm{L} \text { of calcium, } 0.9 \mathrm{mmol} / \mathrm{L} \text { of phosphate, } 0.15 \mathrm{M} \text { of potassium chloride, Tris } \\
\text { buffer, and } 0.05 \mu \mathrm{g} \text { of fluoride } / \mathrm{mL}\end{array}$ \\
\hline
\end{tabular}

\section{D Non-Contact Profilometry Analysis}

The acid-resistant nail varnish was removed from the surfaces of all samples with acetone P.A. to allow the analysis of experiment results.

The loss of tooth structure (TSL) in $\mu \mathrm{m}$ was analyzed by measuring the height difference between the experimental area exposed to the erosive-abrasive challenge and the unexposed area, using 3D non-contact chromatic confocal chromatic prophylometry (Nanovea PS50 Optical, Nanovea Inc., Irvine, CA, USA). The height differences between the unexposed area and the treated area, after removing the resistant acid varnish, were measured. For correct positioning of the blocks on the profilometer, $1 \mathrm{~mm}$ was measured for each side of the center of the block. With this, three measurements were performed with a distance of $100 \mu \mathrm{m}$ from each. The areas were measured in $\mu \mathrm{m}$, with the average of the three TSL measurements for each group. Measurements were performed using a chromatic confocal sensor, with an axial source of white light, a scanning speed of $2 \mathrm{~m} / \mathrm{s}$ and a refractive index of 10,000. 3D profilometry images were also taken to allow the assessment of the topographic characteristics of the superficial enamel at the end of the experiment. In the images, the blue color indicates an increased amount of TSL, while the red color indicates less TSL [22].

\section{Scanning Electron Microscopy (SEM) Analysis}

Two enamel blocks from each group were randomly selected and prepared for SEM analysis (6460LV; JEOL, Tokyo, Japan) of the qualitative changes to the enamel outer layer and for comparing the two areas of study. The blocks were fixed on stubs with double-faced carbon tape and covered with a 30- $\mu \mathrm{m}$ gold layer. The specimens were examined with the same SEM system operating at $20 \mathrm{kV}$ in a low-vacuum mode (45 Pa). Observations were carefully performed through the enamel and images were acquired in a standard magnification of $2,000 \times$.

The researchers who carried out the analyzes in profilometry (TSL) and in SEM were blind, they did not know which product contained in each group, as well as for the statistical analyzes (Figure 1). 


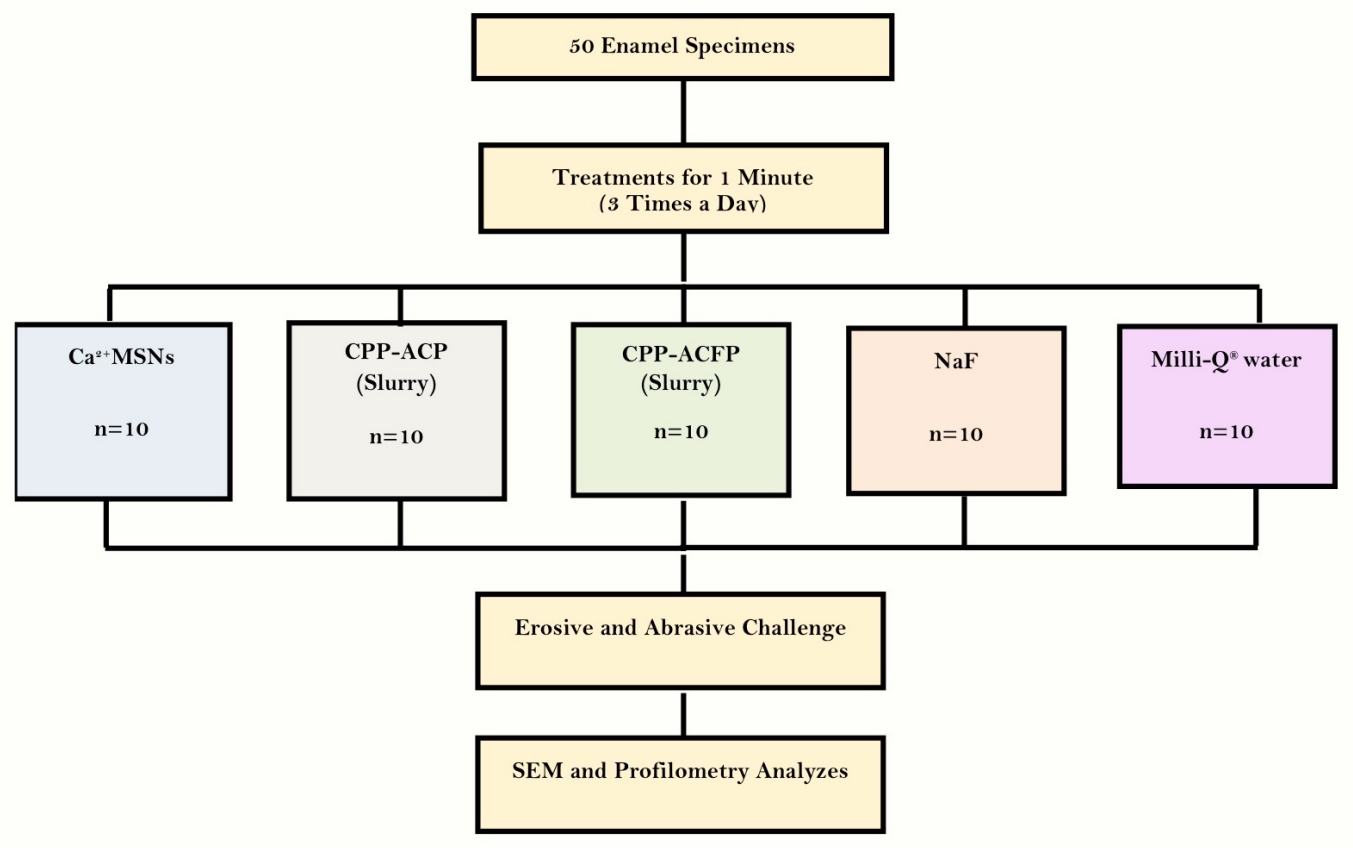

Figure 1. Study flowchart.

Statistical Analysis

The non normal distribution of the data was verified using the Shapiro-Wilk test. The statistical analysis of TSL was performed using the nonparametric Kruskall-Wallis test, followed by the Mann-Whitney U test $(\mathrm{p}<0.05)$. SEM and 3D profilometry images were descriptively analyzed.

\section{Results}

Only the $\mathrm{Ca}^{2+} \mathrm{MSN}$ and CPP-ACFP treatments were able to significantly reduce TSL after the erosion/abrasion challenge compared with the negative control $(\mathrm{p}<0.05)$. There were no significant differences in TSL among the $\mathrm{Ca}^{2+} \mathrm{MSN}$, CPP-ACP, CPP-ACFP and NaF treatments ( $\left.\mathrm{p}>0.05\right)$. TSL values for the CPP$\mathrm{ACP}$ and $\mathrm{NaF}$ treatments were not significantly different from that for the negative control (p>0.05) (Table 2).

Table 2. Median (maximum and minimum) TSL values for the different treatments.

\begin{tabular}{lcc}
\hline \multicolumn{1}{c}{ Treatments } & TSL & \\
\hline $\mathrm{Ca}^{2+}-\mathrm{MSNs}$ & Median $($ Maximum and Minimum $)$ & p-value* $^{*}$ \\
$\mathrm{CPP}-\mathrm{ACP}$ & $10.95(20.93 / 9.21)^{\mathrm{a}}$ & 0.018 \\
$\mathrm{CPP}-\mathrm{ACFP}$ & $12.56(18.38 / 10.92)^{\mathrm{a}, \mathrm{b}}$ & $>0.05$ \\
$\mathrm{NaF}$ & $10.80(27.06 / 8.98)^{\mathrm{a}}$ & 0.026 \\
Water (Negative Control) & $12.26(12.99 / 8.19)^{\mathrm{a}, \mathrm{b}}$ & $>0.05$ \\
\hline Kruskal-Wallis and Mann-Whitney tests; Different letters represent statistical difference $(\mathrm{p}<0.05) ;{ }^{*}$ The $\mathrm{p}-$-value
\end{tabular}
represents a statistical difference comparing the products with the negative control.

The 3D images generated by the profilometry analysis are shown in Figure 2. The greatest difference between the unexposed and experimental areas was observed for the G5 group, which was evident based on the colour variability of the image. Colour variability was less evident in images from the other groups compared with the negative control. The same features were observed in the images obtained by SEM analysis (Figure 3); the G5 group showed the greatest differences between the unexposed and experimental areas. Samples treated with $\mathrm{CPP}-\mathrm{ACP}$ and $\mathrm{NaF}$ presented increase in pore depth and areas with more massed surface and 
small depressions. The images with fewer signs of porosity and surface alterations correspond with samples from the groups treated with CPP-ACFP and $\mathrm{Ca}^{2+} \mathrm{MSN}$.

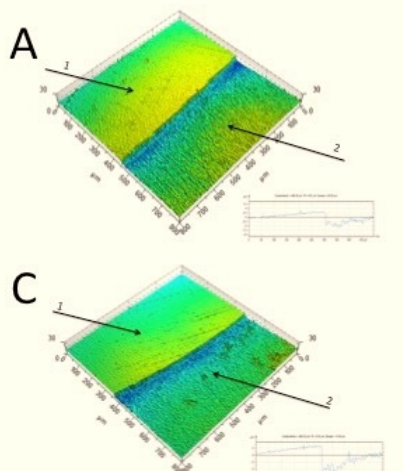

E

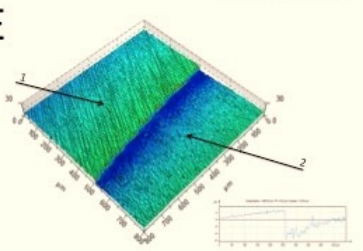

B

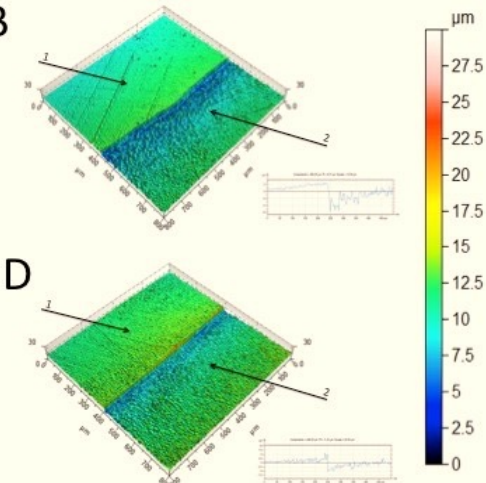

Figure 2. Image and graphical representation of the surface enamel samples after treatments and erosive/abrasive challenge. (A) Calcium mesoporous silica nanoparticles, (B) CPP-ACP, (C) CPPACFP, (D) NaF and (E) Negative control. The number 1 represents the unexposed area, and the number 2 represents the exposed area (treatment and erosive/abrasive challenge).

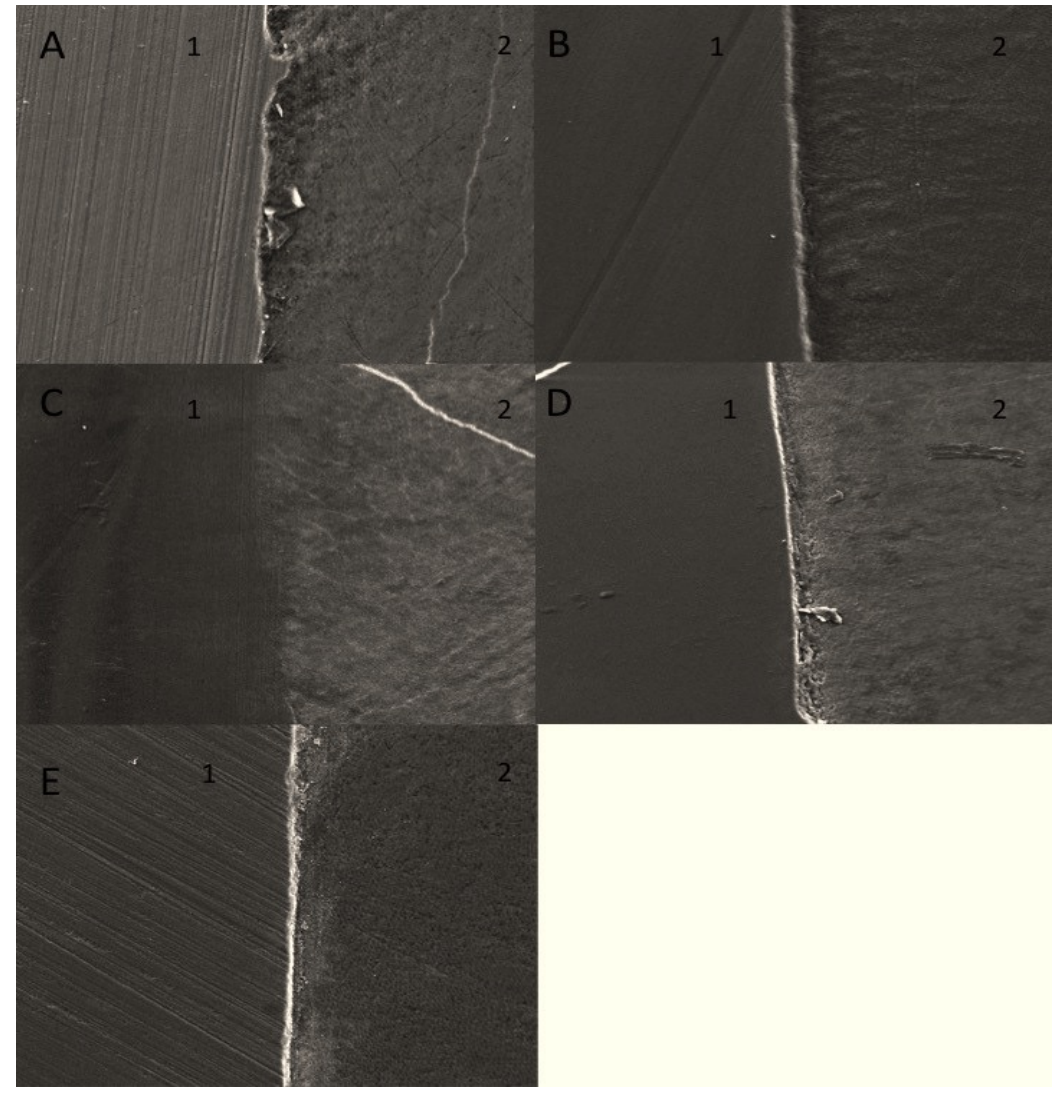

Figure 3. Surface SEM images of the enamel samples after treatments and erosive/abrasive challenge, at a magnification of 500X. (A) Calcium mesoporous silica nanoparticles, (B) CPP-ACP, (C) CPPACFP, (D) NaF and (E) Negative control. The number 1 represents the unexposed area, and the number 2 represents the area exposed to the erosive/abrasive challenge. 


\section{Discussion}

This study compared the ability of $\mathrm{Ca}^{2+} \mathrm{MSN}$ to protect against erosive tooth wear /abrasion with those of other commonly used products with calcium and/or fluoride. The $\mathrm{Ca}^{2+} \mathrm{MSNs}$ demonstrated a similar degree of effectiveness as CPP-ACFP and performed better than the control group at reducing TSL.

Silica nanoparticles have been demonstrated to have the capability to deliver associated molecules such as EGCG (epigallocatechin-3-gallate-encapsulated) - Nano-hydroxyapatite, Ca and P with good control [23,24]. In the present study, the mesoporous silica nanoparticle was used as a novel and high-standard vehicle to increase the bioavailability of calcium molecules and to reduce the erosive tooth wear. This capacity was demonstrated by the positive results obtained from the $\mathrm{Ca}^{2+} \mathrm{MSN}$ s treated group. The present authors believe that the presence of calcium favoured the reduction of TSL, by the current MSN presenting a high loading capacity of calcium. One may suppose that the calcium available in the MSN could be delivered in the interface among eroded enamel surface and the oral environment created in vitro and therefore being responsible for less erosive loss. Moreover, MSN presents a reasonably low-degradable rate, which means a more stable compound [25].

The CPP-ACFP treatment also demonstrated a protective capability to minimize the effects of erosive tooth wear and abrasion. This protective capability is likely due to the effect facilitated by the addition of fluoride to the nanocomplex, while the ability to reduce tooth TSL against erosive tooth wear combined with abrasion has also been described in the literature for CPP-ACP/NaF varnish $\left(5 \% \mathrm{NaF}\right.$, MI Varnish ${ }^{\mathrm{TM}}$, GC America, Alsip, IL, USA) [22].

The use of CPP-ACFP resulted in better protection from TSL than the use of nonfluoridated CPPACP, which was not able to reduce the abrasion-associated erosive tooth wear, suggesting that the calcium concentration of CPP-ACP was not sufficient enough to act effectively in minimize the effects of erosive tooth wear.

Although both CPP-ACP and CPP-ACFP are stable nanocomplexes that behave as vehicles for calcium and phosphate, only CPP-ACFP has fluoride ions incorporated into its composition [26]. Thus, the better performance observed for CPP-ACFP is likely due to the bioavailability of both fluoride and calcium. This beneficial result with the use of CPP-ACP with fluoride is also due to a great affinity for the calcium present in the saliva to form calcium fluoride $\left(\mathrm{CaF}_{2}\right)$. Products containing calcium and fluoride in their composition, according to recent studies, have formed protective layers to prevent acid contact with the enamel surface and, consequently, the loss of dental tissue [27].

During the de- and remineralization processes, fluoride can be incorporated into hydroxyapatite, making the dental enamel more resistant to the dissolution of minerals [8]. In addition, the potential remineralization effects of $\mathrm{CPP}-\mathrm{ACP}$ on teeth with erosion lesions, either with or without dental abrasions, were observed previously in in situ studies [18,28].

Although the non-fluoridated CPP-ACP does not have the stability provided by fluoride, it has good results in in vitro studies against dental caries because the technology in this nanocomplex adheres to plaques and gradually releases the calcium and phosphate ions onto the tooth surface [13] $\mathrm{NaF}$ has been used for the prevention and treatment of mineral loss due to the formation of $\mathrm{CaF}_{2}$, which acts as a physical barrier for the protection of dental structures [1,8]. However, in the present study, the observed TSL for the NaF-treated samples was similar to that observed in the control group. This may be due to the 900 ppm fluoride concentration used in the present study, which was below the $1,100 \mathrm{ppm}$ concentration that has been shown to be effective for preventing erosive tooth wear; $900 \mathrm{ppm}$ was selected to allow the concentration of $\mathrm{NaF}$ to be similar to the fluoride concentration used in the fluoridated CPP-ACP [20,29-32]. 
However, studies that used fluoride pastes showed its effectiveness in reducing the loss of tooth structure by erosive tooth wear -abrasion, due to its association with the cytosan compound, since the molecule forms stable multilayer at acid $\mathrm{pH}$, resulting in less enamel loss. Furthermore, the presence of this polysaccharide forms multilayers on the enamel surface, since it binds to mucin present in saliva [27].

In this study, Sprite Zero ${ }^{\text {TM }}$ was chosen for its ability to provoke erosive processes, reflecting the etiology of noncarious lesions diagnosed in clinical practice and simulating a clinical situation wherein the patient consumes acidic drinks every day. Other in vitro studies have also used the soft drink to promote erosive challenges [33] and in erosive/abrasive challenges [22,27,34]. The use of a control group demonstrated the validity of erosive cycling, with blocks that did not receive treatments having much higher TSL values compared with the other groups.

A toothbrush machine was used to promote the abrasive process after erosion in vitro to simulate tooth brushing after the consumption of an acidic beverage [35]. Although the literature reports that abrasive toothpastes are the primary abrasive agents [4] other agents with less abrasive potential, such as toothbrushes and tongue friction, can promote tooth wear due to the increased brittleness of dental structures after exposure to acids [36] 3D noncontact profilometry was chosen as the method to analyze the results because it is the most commonly used option in studies that perform erosion and abrasion in vitro. In addition, 3D noncontact profilometry does not cause the destruction of the studied blocks and boasts the optimal sensitivity for surfaces that present different levels of height, a characteristic that was utilized in this study to quantify the TSL of the experimental areas $[22,36,37]$. To complement the 3D noncontact profilometry analysis, which facilitates the measurement of height differences between the control and experimental sides, photomicrographs were obtained by SEM. Thus, it was also possible to qualitatively evaluate the surface alterations on the exposed area of the specimens in response to the erosive/abrasive challenge and to their respective treatments.

Although the in vitro model can be considered a limitation of our study, since it does not fully simulate the oral cavity, artificial saliva and soft drink were chosen to make the experiment as similar as possible with the oral cavity and clinical situation. Another possible limitation would be the comparison of products in the form of solution and toothpaste, as they have different viscosities, however the making of slurrys was performed to mimic toothpastes already diluted in the oral cavity.

The null hypothesis of the present study was rejected, since the new product had a positive effect in minimizing the loss of tooth structure when compared to commonly used products, after erosion-tooth abrasion challenges.

\section{Conclusion}

This study, which aimed to evaluate the use of $\mathrm{Ca}^{2+} \mathrm{MSN}$ in reducing the loss of tooth enamel after challenges of erosion and abrasion, comparing with commonly used products, concluded that $\mathrm{Ca}^{2+} \mathrm{MSNs}$ obtained results in minimizing the loss of tooth structure (TSL) similar to a product already marketed as CPPACFP, showing less signs of change in topography and changes in surface, showing better results compared to positive and negative control. Future in situ and in vivo studies using $\mathrm{Ca}^{2+} \mathrm{MSNs}$ should be performed to demonstrate its protective effects and ultimately support its use in clinical practice.

\section{Authors' Contributions}

IBSJ (D) 0000-0003-1718-7070 Investigation, Formal Analysis, Writing - Original Draft Preparation and Writing - Review and Editing. 
AKA (D) 0000-0003-4774-1204 Formal Analysis and Writing - Review and Editing.

FMTC (D) 0000-0002-7058-5724 Investigation, Formal Analysis and Writing - Review and Editing.

KLFL (D) 0000-0002-0113-6810 Investigation, Formal Analysis and Writing - Review and Editing.

TIV (D) 0000-0003-4824-9131 Investigation, Formal Analysis and Writing - Review and Editing.

LMC (D) 0000-0002-4550-5729 Conceptualization, Methodology, Validation and Writing - Review and Editing.

RFS (D) 0000-0002-9739-0169 Conceptualization, Methodology, Validation and Writing - Review and Editing.

LCM (D) 0000-0003-1026-9401 Conceptualization, Methodology and Writing - Review and Editing.

All authors declare that they contributed to critical review of intellectual content and approval of the final version to be published.

\section{Financial Support}

This study was financed in part by the PIBIC, by the Coordenação de Aperfeiçoamento de Pessoal de Nível Superior Brasil (CAPES) - Finance Code 001, by Conselho Nacional de Desenvolvimento Científico e Tecnológico - CNPq (Grant No. 303535/2016-4) and Fundação Carlos Chagas Filho de Amparo à Pesquisa do Estado do Rio de Janeiro - FAPERJ (Process Number E-26/202.924/2017 and E-26/201.865/2018).

\section{Conflict of Interest}

The authors declare no conflicts of interest.

\section{References}

[1] Carvalho TS, Colon P, Ganss C, Huysmans MC, Lussi A, Schlueter N, et al. Consensus report of the European Federation of Conservative Dentistry: erosive tooth wear-diagnosis and management. Clin Oral Investig 2015; 19(7):1557-61. https://doi.org/10.1007/s00784-015-1511-7

[2] Huysmans MCDNJM, Chew HP, Ellwood RP. Clinical studies of dental erosion and erosive wear. Caries Res 2011; 45(Suppl 1):60-68. https://doi.org/10.1159/000325947

[3] Ganss C. Definition of erosion and links to tooth wear. Monogr Oral Sci 2006; 20:9-16. https://doi.org/10.1159/000093344

[4] Wiegand A, Schwerzmann M, Sener B, Magalhães AC, Roos M, Ziebolz D, et al. Impact of toothpaste slurry abrasivity and toothbrush filament stiffness on abrasion of eroded enamel - an in vitro study. Acta Odontol Scand 2008; 66(4):231-5. https://doi.org/10.1080/00016350802195041

[5] Assunção CM, Lussi A, Rodrigues JA, Carvalho TS. Efficacy of toothpastes in the prevention of erosive tooth wear in permanent and deciduous teeth. Clin Oral Investig 2019; 23(1):273-84. https://doi.org/10.1007/s00784-018-2434-X

[6] Newbrun E. What we know and do not know about fluoride. J Public Health Dent 2010; 70(3):227-33. https://doi.org/10.1111/j.1752-7325.2010.00171.x

[7] Marinho VC,C Worthington HV, Walsh T, Clarkson JE. Fluoride varnishes for preventing dental caries in children and adolescents. Cochrane Database Syst Rev 2013; (7):CDo02279. https://doi.org/10.1002/14651858.CDo02279.pub2

[8] Lussi A, Hellwig E, Klimek J. Fluorides - Mode of action and recommendations for use. Schweiz Monatsschri Zahnmed 2012; 122(11):1030-42.

[9] Alexandria AK, Valença AMG, Cabral LM, Maia LC. Fluoride varnishes against dental erosion caused by soft drink combined with pediatric liquid medicine. Braz Dent J 2017; 28(4):482-8.

https://doi.org/10.1590/0103-6440201701567

[10] Algarni AA, Mussi MCM, Moffa EB, Lippert F, Zero D,T Siqueira WL, et al. The impact of stannous, fluoride ions and its combination on enamel pellicle proteome and dental erosion prevention. PloS One 2015; 10(6):e0128196. https://doi.org/10.1371/journal.pone.0128196

[11] Hove LH, Holme B, Young A, Tveit AB. The erosion-inhibiting effect of TiF4, SnF2, and NaF solutions on pelliclecovered enamel in vitro. Acta Odontol Scand 2007; 65(5):259-64. https://doi.org/10.1080/00016350701477581

[12] Cochrane NJ, Reynolds EC. Calcium phosphopeptides-mechanisms of action and evidence for clinical efficacy. Adv Dent Res 2012; 24(2):41-7. https://doi.org/10.1177/0022034512454294

[13] Reynolds EC. Casein phosphopeptide-amorphous calcium phosphate: the scientific evidence. Adv Dent Res 2009; 21(1):25-9. https://doi.org/10.1177/0895937409335619

[14] Cross KJ, Huq NL, Reynolds EC. Casein phosphopeptides in oral health - chemistry and clinical applications. Curr Pharm Des 2007; 13(8):793-800. https://doi.org/10.2174/138161207780363086

[15] Reynolds EC. Calcium phosphate-based remineralization systems: scientific evidence? Aust Dent J 2008; 53(3):26873. https://doi.org/10.1111/j.1834-7819.2008.00061.x

[16] Cochrane NJ, Shen P, Yuan Y, Reynolds EC. Ion release from calcium and fluoride containing dental varnishes. Aust Dent J 2014; 59(1):100-5. https://doi.org/10.1111/adj.12144 
[17] Arcos D, Vallet-Regí M. Bioceramics for drug delivery. Acta Mater 2013; 61(3):890-911. https://doi.org/10.1016/j.actamat.2012.10.039

[18] Oliveira LS, Marçal L, Rocha LA, de Faria EH, Ciuffi KJ, Nassar EJ, et al. Photoinitiator and anesthetic incorporation into mesoporous silica. Powder Technol 2018; 326:62-8. https://doi.org/10.1016/j.powtec.2017.12.044

[19] Chiang Y, Lian H, Leo S, Wang S, Yamauchi Y, Wu KCW. Controlling particle size and structural properties of mesoporous silica nanoparticles using the Taguchi method. J Phys Chem C 2011; 115(27):13158-65. https://doi.org/10.1021/jp201017e

[20] Lussi A. Erosive tooth wear - a multifactorial condition of growing concern and increasing knowledge. Monogr Oral Sci 2006; 20:1-8. https://doi.org/10.1159/000093343

[21] West NX, Joiner A. Enamel mineral loss. J Dent 2014; 42(Suppl 1):S2-11. https://doi.org/10.1016/S0300-5712(14)50002-4

[22] Alexandria AK, Vieira TI, Pithon MM, Fidalgo TKS, Fonseca-Gonçalves A, Valença AMG, et al. In vitro enamel erosion and abrasion-inhibiting effect of different fluoride varnishes. Arch Oral Biol 2017; 77:39-43. https://doi.org/10.1016/j.archoralbio.2017.01.010

[23] Zhang JF, Wu R, Fan Y, Liao S, Wang Y, Wen ZT, et al. Antibacterial dental composites with chlorhexidine and mesoporous silica. J Dent Res 2014; 93(12):1283-9. https://doi.org/10.1177/0022034514555143

[24] Yu J, Yang H, Li K, Ren H, Lei J, Huang C. Development of epigallocatechin-3-gallate-encapsulated nanohydroxyapatite/mesoporous silica for therapeutic management of dentin surface. ACS Appl Mater Interfaces 2017; 9(31):25796-807. https://doi.org/10.1021/acsami.7b06597

[25] Cauda V, Schlossbauer A, Bein T. Bio-degradation study of colloidal mesoporous silica nanoparticles: Effect of surface functionalization with organo-silanes and poly(ethylene glycol). Microporous and Mesoporous Mater 2010; 132(1-2): 60-71. https://doi.org/10.1016/j.micromeso.2009.11.015

[26] Ye XY, Zheng HY, Cheng SL, Cheng H, Yu H. Effects of casein phosphopeptide-amorphic calcium phosphate on enamel erosion: An in situ study. Zhonghua Kou Qiang Yi Xue Za Zhi 2018; 53(3):195-200. https://doi.org/10.3760/cma.j.issn.1002-0098.2018.03.011

[27] Schlueter N, Klimek J, Ganss C. Randomised in situ study on the efficacy of a tin/chitosan oothpaste on erosiveabrasive enamel loss. Caries Res 2013; 47(6):574-81. https://doi.org/10.1159/000351654

[28] Srinivasan N, Kavitha M, Loganathan SC. Comparison of the remineralization potential of CPP-ACP and CPP-ACP with $900 \mathrm{ppm}$ fluoride on eroded human enamel: an in situ study. Arch Oral Biol 2010; 55(7):541-4. https://doi.org/10.1016/j.archoralbio.2010.05.002

[29] Comar LP, Gomes MF, Ito N, Salomão PA, Grizzo LT, Magalhaes AC. Effect of NaF, $\mathrm{SnF} 2$, and TiF4 toothpastes on bovine enamel and dentin erosion-abrasion in vitro. Int J Dent 2012 2012; 2012:134350. https://doi.org/10.1155/2012/134350

[30] Magalhães AC, Rios D, Moino AL, Wiegand A, Attin T, Buzalaf MAR. Effect of different concentrations of fluoride in dentifrices on dentin erosion subjected or not to abrasion in situ/ex vivo. Caries Res 2008; 42(2):112-6. https://doi.org/10.1159/000117807

[31] Moron BM, Miyazaki SSH, Ito N, Wiegand A, Vilhena F, Buzalaf MAR, et al. Impact of different fluoride concentrations and $\mathrm{pH}$ of dentifrices on tooth erosion/abrasion in vitro. Aust Dent J 2013; 58(1):106-11. https://doi.org/10.1111/adj.12016

[32] Moretto MJ, Magalhães AC, Sassaki KT, Delbem ACB, Martinhon CCR. Effect of different fluoride concentrations of experimental dentifrices on enamel erosion and abrasion. Caries Res 2010; 44(2):135-40. https://doi.org/10.1159/000302902

[33] Magalhães AC, Levy FM, Rios D, Buzalaf MAR. Effect of a single application of TiF4 and NaF varnishes and solutions on dentin erosion in vitro. J Dent 2010; 38(2):153-7. https://doi.org/10.1016/j.jdent.2009.09.015

[34] Magalhães AC, Romanelli AC, Rios D, Comar LP, Navarro RS, Grizzo LT, et al. Effect of a single application of TiF4 and $\mathrm{NaF}$ varnishes and solutions combined with $\mathrm{Nd}$ :YAG laser irradiation on enamel erosion in vitro. Photomed Laser Surg 201 1; 29(8):537-44. https://doi.org/10.1089/pho.2010.2886

[35] Levy FM, Magalhães AC, Gomes MF, Comar LP, Rios D, Buzalaf MAR. The erosion and abrasion-inhibiting effect of $\mathrm{TiF} 4$ and $\mathrm{NaF}$ varnishes and solutions on enamel in vitro. Int $\mathrm{J}$ Paediatr Dent 2012; 22(1):11-6. https://doi.org/10.1111/j.1365-263X.2011.01151.x

[36] Amaechi BT, Higham SM, Edgar WM. Influence of abrasion in clinical manifestation of human dental erosion. J Oral Rehabil 2003; 30(4):407-13. https://doi.org/10.1046/j.1365-2842.2003.01098.x

[37] Vieira A, Overweg E, Ruben JL, Huysmans MCDNJM. Toothbrush abrasion, simulated tongue friction and attrition of eroded bovine enamel in vitro. J Dent 2006; 34(5):336-42. https://doi.org/10.1016/j.jdent.2005.07.010 